feleisens. Man verfährt demnach, wie ich fand, besser, wenn man das innig gemengte Pulver in einen rothgliihenden Schmelztiegel portionenweise einträgt, und jedesmal wartet, wie bei ähnlicher Bereitung des Schwefeleisens, bis die innige Verbindung durch das bezeichnende Erglühen eintritt.

Nachdem Alles eingetragen, wird der Tiegel bedeckt, noch eine kurze Zeit im Glühen erhalten, sodann die erkaltete Masse weiter behandelt.

Die so dargestellte Titansäuro ist verunreinigt mit Eisen und Spuren von Mangan und Zinn, und stellt ein gelblichweisses Pulver dar. 100 Theile Titaneisen lieferten gewöhnlich 85-90 Theile Titansäure.

Die Titansäure aus dem Rutil wird bereitet, indem das geschlämmte Mineral mit 4 Theilen von einem Gemenge aus gleichen Theilen zerfallenem kohlensaurem Natron und trocknem kohlensaurem Kali innig gemengt, geschmolzen, die erkaltete Masse vermittelst Wassers von dem überschüssigen Alkali befreit, der Rückstand, grösstentheils titansaures Kali und.Natron, in concentrirter Salzsäure aufgelöst, mit Wasser verdiunnt, filtrirt und nun mit Aetzammoniak präcipitirt wird.

Der Niederschlag getrocknet und geglüht, giebt ebenfalls eine gelblichweisse Titansäure, und zwar in derselben Menge, wie aus dem Titaneisen.

\title{
Ueber die bei der Anwendung des Marsh'schen Apparates gemachte Bemerkung, dass auch Wismuth, ferner Schwefelarsen und Schwefel- antimon im Wasserstoff löslich und durch Verbrennen desselben wieder abgeschieden werden können;
}

\author{
ron \\ D. Friedrich Meurer, \\ Apotheker zu Dresden.
}

Die vielen Versuche, welche ich mit der Methode von Marsh angestellt habe, theils um das Arsen in anorgani-

Arch. d. Pharm. LXXXVI. Bds. 1. Hft. 
schen, theils in organischen Gebilden aufzufinden, hat mich Einiges finden lassen, was sowohl für diese Methode selbst, als auch im Allgemeinen für die Chemie nicht ohne Interesse ist, und was ich mir erlaube hier mitzutheilen.

Zuerst fand ich, dass auch Wismuth sich in Wasserstoffgas löst und dass das so erhaltene Wismuthwasserstoffgas beim Anbrennen einen Fleck auf der Porcellanplatte zurücklässt, der sich schon im Aeussern von einem Arsenfleck unterscheidet, aber auch durchaus nicht bei fernerer Prüfung damit verwechselt werden kann. Das Wasserstoffgas löst nur wenig auf, und erzeugt sich nur bei energischer Zersetzung des Viassers oder der Salzsäure durch Zink, wenn man dem Gemisch etwas Wismuthchlorid zugesetzt hat; die Flamme ist nicht so weiss, als bei Arsenwasserstoff, der Fleck selbst nur klein, legt sich mehr nur in der Mitte der Flamme oder doch nicht in weiterm Kreise an, er ist sehr blassgrau, nicht so in alle Farben spielend, löst sich in der Labarraque'schen Flüssigkeit nicht auf u. s. w. Ja bei gemischten Flecken, d. h. aus Wismuth und Arsen bestehenden, wurde der äussere Rand von der Bleichflüssigkeit aufgelöst, aber der Mittelpunct von Wismuth blieb zurück. Hierauf beruhte es wohl, dass von Einigen auch reines Magister. bismuthi für arsenhaltig erklärt werden konnte, und dass im Gegentheil Andere behaupten, es wäre niemals Arsen im Magisterium bismuthi, weil nämlich der erhaltene Fleck ein anderes Ansehen hat. Mechanisch aber war das Wismuth nicht mit herübergerissen, denn ich erhielt es auch dann, wenn ein Asbestrohr vorgelegt worden war. Schwierig wird die Bestimmung dadurch, dass man, wenn Arsen mit dem Wismuth gemischt ist, bald nur reines Arsen, bald Wismuth, bald gemischte Flecke erhält, wodurch dann die Prüfung aller Flecke nöthig wird. Es wird aber auch dieser Uebelstand ubergangen, wenn man die fraglich auszuscheidenden Metalle in einer Glasröhre auffänt. - Um Wismuth zu untersuchen, muss man es immer vorher in basisch-salpetersaures verwandeln und dann in Salzsäure auflösen, und diese Lösung erst in den zur Wasserstoff- 
Entwickelung vorgerichteten Apparat bringen. Ich fand ferner, dass sich nicht bloss einfache, sondern auch zusammengesetzte Körper in dem Wasserstoffgase lösten, nämlich Schwefelarsen und Schwefelantimon. Diese Bemerkung schien mir interessant für die Unterscheidung dieser beiden Dinge, und man kann sie auch dazu benutzen, doch giebt es der Unterscheidungsmittel für Arsen und Antimon so viele, dass dadurch wohl nichts weiter gewonnen wird; mehr Werth scheint mir diese Bemerkung für die Chemie überhaupt zu haben, erstens deshalb, weil bisher es nicht bekannt war, dass diese Schwefelverbindungen in Wasserstoffgas löslich waren, und durch Verbrennen des Wasserstoffgases wieder abgeschieden werden könnten, und weil hierdurch auch eine Verunreinigung des Schwefelwasserstoffgases mit Schwefelarsen und Schwefelantimon möglicherweise statt finden kann.

Um diese Verbindungen zu erhalten, setzt man am besten der zu prüfenden arsen- oder antimonhaltigen Flüssigkeit etwas Aqua hydrosulphurata hinzu und schüttet es dann in das zur Wasserstoffgas - Entwickelung vorgerichtete Glas : es ist dies zweckmässiger, als wenn man durch Schwefeleisen erst das Schwefelwasserstoffgas gleichzeitig entwickelt; denn es geschicht dann die Bildung ungleich und man erhält anfangs noch Flecke von Arsen und Antimon, und erst später die von Schwefelarsen und Schwefelantimon. - Vom blossen Schwefelfleck, den man beim Verbrennen von Schwefelwasserstoffgas erhält, unterscheiden sie sich leicht, denn dieser ist immer sehr unbedeutend und löst sich nicht in Aetzammoniakfluissigkeit auf. Arsen und Antimon unterscheiden sich auffallend durch ihre Farbe, weniger leicht ist es bei gemischten Flecken. - Zuerst erhielt ich zufällig einen Fleck von Schwefelarsen, als aus Versehen Schwefelarsen in den Marsh'schen Apparat geschüttet worden war; ich wusste lange nicht, für was dieser Fleck zu halten sei, bis endlich die Löslichkeit desselben in Ammoniak und seine fernere Prifung ihn uns als Schwefelarsen erkennen liess, worauf dann auch der Grund, wodurch er entstanden, erkannt wurde. 
Meine vielen Geschäfte für das praktische Lcben verhinderten mich, diesen theoretischen wissenschaftlichen Untersuchungen ferncre Zeit $\mathrm{zu}$ widmen, ich muss mir das für künftig vorbehalten oder Andern überlassen, die das Glück günstiger gestellt bat*).

\section{Veber ein neutes arsensaures Doppelsalz;}

von

Dr. Hr. Ba umann in Meiningen.

Die Bildung dieses Salzes wurde gelegentlich bei einer Analyse beobachtet. Da in den mir zu Gebote stehenden IIandbuichern der Chemie über dieses Salz keine Auskunft zu erlangen war, so wurde dasselbe einer Analyse unterworfen, deren Resultat ich hier mittheile.

Bringt man zu einer mässig verdünnten wässerigen Lösung von Arsensäure eine Lösung von salpetersaurem Kalk, so entsteht kein Niederschlag, weil der gebildete arsensaure Kalk von der frei gewordenen Salpetersäure sogleich wieder aufgelöst wird. Fügt man aber Ammoniak hinzu, so wird dadurch diese Säure neutralisirt und folglich ein Niederschlag von arsensaurem Kalk hervorgebracht. Bei cinem Leberschusse von Ammoniak verwandelt sich aber dieser weisse voluminüse Niederschlag sehr bald in schöne Nadeln.

Dieselben Nadeln entstehen auch, wenn man mittelst Kalkwassers einen nicht allzugrossen Niederschlag in einer Auflösung von Arsensäure bewirkt und diesem Niederschlag nebst der Flüssigkeit, worin er entstand, Ammoniak hin-

-) Diese hier gegebene Mittheilung wurde in der Generalversammlung zu Blankenbur̀g vorgetragen und dabei zugleich eine Porcellantafel vorgelegt, auf welcher die nach Mars h's Methode erzeugten Flecke von Wismuth, Wismuth und Arsen, von Schwefel, Schwefelarsen, Schwefelantimon, von Schwefelarsen und Schwefelantimon, und der Vollständigkeit wegen auch von Arsen, Antimon und von einem Gemisch von Arsen und Antimon zusammengestellt waren. 